\title{
Trends in breastfeeding and complementary feeding practices in Pakistan, 1990-2007
}

\author{
Hafsa Muhammad Hanif
}

\begin{abstract}
Background: Breastfeeding and complementary feeding practices have profound implications for the maternal and child health status of a society. Feeding practices in Pakistan are suboptimal, leading to adverse outcomes on child health. In Pakistan, the Maternal, Neonatal and Child Health (MNCH) Program, in collaboration with several international organizations, including WHO and UNICEF, is working to improve these feeding practices in the country. The aim of this paper is to evaluate the effectiveness of these programs.
\end{abstract}

Methods: Estimates on the various indicators for infant and young child feeding proposed by WHO were analyzed in light of the Pakistan Demographic and Health Surveys (1990-91 and 2006-07) and several other national studies conducted since 1995.

Results: Nearly half the core and optional indicators have improved over the years, though modestly; the others have demonstrated no statistically significant improvement over the years. Of the five indicators required in the WHO tool for the assessment of infant and young child feeding, introduction of complementary foods, bottlefeeding, and early initiation of breastfeeding, stand in the poor category, while exclusive breastfeeding and duration of breastfeeding fall in the fair category, suggesting an overall poor status.

Conclusions: There is considerable scope to improve breastfeeding and complementary feeding in Pakistan. Further programs should focus on improving the following indicators that have shown no significant development: early initiation of breastfeeding, exclusive breastfeeding under six months, continued breastfeeding at two years, age appropriate feeding, and bottle feeding. Effective implementation of interventions that are known to improve breastfeeding practices is imperative, as is further research to yield data that can lead future endeavors.

Keywords: breastfeeding, complementary feeding, infant and young child feeding indicators, Pakistan

\section{Background}

Breastfeeding and complementary feeding practices have long been demonstrated to have significant implications for maternal and child health. Healthy breastfeeding practices reduce child mortality and morbidity, and improve immunity in children, besides being essential for their optimal growth and development [1]. In mothers, breastfeeding is associated with enhanced emotional attachment to the infant, reduced risk of breast and endometrial cancer, increased duration of post partum amenorrhea, and consequent birth spacing, as well as several other health benefits [1]. The World Health Organization recommends that infants be exclusively

Correspondence: hafsa_hmh@hotmail.com

Dow Medical College, Dow University of Health Sciences, Baba-e-Urdu Road, Karachi 74400 , Pakistan breastfed for the first six months, followed by breastfeeding along with complementary foods for up to two years of age or beyond [2].

Even though nearly all children in Pakistan are breastfed [3], feeding practices are suboptimal, leading to adverse outcomes on child health, worsening the already poor state of child health and nutrition in the country, and overburdening the meager health coverage. Hence, improving breastfeeding and infant feeding practices is an important means used by the World Health Organization to improve child health in Pakistan and other developing countries [4]. In fact, exclusive breastfeeding for the first six months of postnatal life has been identified as the single most instrumental intervention that can aid in decreasing child mortality and morbidity [5]. 
In Pakistan, the Maternal, Neonatal and Child Health (MNCH) Program, Ministry of Health, in collaboration with WHO, UNICEF and USAID, is working towards the improvement of the health status indicators of the country. Breastfeeding and complementary feeding practices are among the many important issues that the Program addresses [6] through training and the network of community workers and health centers.

The objective of this article is to present the trends of breastfeeding and complementary feeding practices in Pakistan since the 1990s in order to assess the degree of effectiveness of the efforts of the MNCH Program, WHO, various NGOs, and other stakeholders in improving feeding practices, and the extent to which they have achieved their objectives. Despite the concern that the issue has received over the years, data on the subject from a single source is lacking. Even in surveys that do have relevant data, several indicators have not been precisely described, and require additional analysis of underlying data to calculate. Hence estimates of feeding practices in collected data, and in comparison to other sources, is timely.

\section{Methods}

The estimates presented in the following research publications were studied: Pakistan Demographic and Health Survey, 1990-1991 [7] [DHS 90-91]; Pakistan Demographic and Health Survey, 2006-2007 [3] [DHS 06-07]; Pakistan Integrated Household Survey, 1998-1999 [8] (Federal Bureau of Statistics) [PIHS 98-99]; Pakistan Integrated Household Survey, 2001-2002 [9] (Federal Bureau of Statistics) [PIHS 01-02]; Pakistan Social and Living Standards Measurement Survey, 2005-2006 [10] (Federal Bureau of Statistics) [PSLM 05-06]; and Pakistan Social and Living Standards Measurement Survey, 2007-2008 [11] (Federal Bureau of Statistics) [PSLM 07-08]. See Table 1.

The indicators for breastfeeding and complementary feeding practices have been adapted from infant and young child feeding indicators recommended by the
World Health Organization [12], and the trends presented below are based on the aforementioned publications. Where data were available, 95\% confidence intervals were calculated for the percentages using the standard formula.

The purpose of this article is not to emulate the detailed definitions and implications of each of the indicators, nor to present their underlying rationales. Readers can access this information in the World Health Organization publication, 'Indicators for assessing infant and young child feeding practices' (Parts I and III) $[13,14]$.

\section{Results}

Table 2 presents the infant and young child feeding indicators as proposed by the World Health Organization [12]. The indicators are classified as 'core' and 'optional', with the following being the most important among the core indicators: early initiation of breastfeeding; exclusive breastfeeding under six months; minimum acceptable diet; and consumption of iron-rich or ironfortified foods. Estimates on the trends of the latter two of these four, along with two other core indicators, namely, minimum dietary diversity and meal frequency, were not given in any publication studied, nor could they be found in other national surveys. Trends of the remaining indicators are presented below.

The calculations for estimates that were not directly reported in the publications, but had to be calculated using the available data, are presented as an additional file [see Additional file 1].

\section{Early initiation of breastfeeding}

The World Health Organization recommends that breastfeeding be started soon after birth, preferably within the first hour [2]. This improves breastfeeding success [15], the health and survival status of newborns, and the emotional attachment of the child to the mother [16]. Early initiation of breastfeeding is the also

Table 1 Summary of surveys

\begin{tabular}{|c|c|c|c|c|}
\hline Title of survey & Conducted by & Coverage & Sample size & Sampling method \\
\hline $\begin{array}{l}\text { Pakistan Demographic and Health Survey, } \\
\text { 1990-91 [7] }\end{array}$ & $\begin{array}{l}\text { National Institute of Population Studies } \\
\text { (Pakistan), and Macro International Inc. }\end{array}$ & National & $\begin{array}{l}7193 \\
\text { households }\end{array}$ & Unspecified \\
\hline $\begin{array}{l}\text { Pakistan Integrated Household Survey, 1998-99 } \\
\text { [8] }\end{array}$ & Federal Bureau of Statistics, Pakistan & National & $\begin{array}{l}16305 \\
\text { households }\end{array}$ & $\begin{array}{l}\text { Multi-stage stratified } \\
\text { random sample }\end{array}$ \\
\hline $\begin{array}{l}\text { Pakistan Integrated Household Survey, 2001-02 } \\
\text { [9] }\end{array}$ & Federal Bureau of Statistics, Pakistan & National & $\begin{array}{c}16182 \\
\text { households }\end{array}$ & $\begin{array}{l}\text { Multi-stage stratified } \\
\text { random sample }\end{array}$ \\
\hline $\begin{array}{l}\text { Pakistan Social and Living Standards } \\
\text { Measurement Survey, 2005-06 [10] }\end{array}$ & Federal Bureau of Statistics, Pakistan & National & $\begin{array}{l}15453 \\
\text { households }\end{array}$ & $\begin{array}{l}\text { Multi-stage stratified } \\
\text { random sample }\end{array}$ \\
\hline $\begin{array}{l}\text { Pakistan Demographic and Health Survey, } \\
\text { 2006-07 [3] }\end{array}$ & $\begin{array}{l}\text { National Institute of Population Studies (Pakistan) } \\
\text { and Macro International Inc. }\end{array}$ & National & $\begin{array}{l}97,687 \\
\text { households }\end{array}$ & $\begin{array}{l}\text { Multi-stage stratified } \\
\text { random sample }\end{array}$ \\
\hline $\begin{array}{l}\text { Pakistan Social and Living Standards } \\
\text { Measurement Survey, 2007-08 [11] }\end{array}$ & Federal Bureau of Statistics, Pakistan & National & $\begin{array}{c}15512 \\
\text { households }\end{array}$ & $\begin{array}{l}\text { Multi-stage stratified } \\
\text { random sample }\end{array}$ \\
\hline
\end{tabular}


Table 2 Indicators for Infant and Young Child Feeding (WHO) [reproduced with permission from EUPHIX: European Union Public Health Information and Knowledge System]

\begin{tabular}{|c|c|}
\hline Core indicators & Optional indicators \\
\hline 1. Early initiation of breastfeeding: & 9. Children ever breastfed: \\
\hline $\begin{array}{c}\text { Proportion of children born in the last } 23.9 \text { months who were put to the } \\
\text { breast within one hour of birth. }\end{array}$ & $\begin{array}{c}\text { Proportion of children born in the last } 23.9 \text { months who were ever } \\
\text { breastfed. }\end{array}$ \\
\hline 2. Exclusive breastfeeding under six months: & 10. Continued breastfeeding at two years: \\
\hline $\begin{array}{c}\text { Proportion of infants } 0-5.9 \text { months of age who are fed exclusively with } \\
\text { breast milk. }\end{array}$ & Proportion of children 20-23.9 months of age who are fed breast milk. \\
\hline 3. Continued breastfeeding at one year: & 11. Age-appropriate breastfeeding: \\
\hline Proportion of children 12-15.9 months of age who are fed breast milk. & $\begin{array}{c}\text { Proportion of children } 0-23.9 \text { months of age who are appropriately } \\
\text { breastfed. }\end{array}$ \\
\hline 4. Introduction of solid, semi-solid or soft foods: & 12. Predominant breastfeeding under six months: \\
\hline $\begin{array}{l}\text { Proportion of infants 6-8.9 months of age who receive solid, semi-solid or } \\
\text { soft foods. }\end{array}$ & $\begin{array}{c}\text { Proportion of infants 0-5.9 months of age who are predominantly } \\
\text { breastfed. }\end{array}$ \\
\hline 5. Minimum dietary diversity: & 13. Duration of breastfeeding: \\
\hline $\begin{array}{c}\text { Proportion of children } 6-23.9 \text { months of age who receive foods from four } \\
\text { or more out of seven food groups. }\end{array}$ & Median duration of breastfeeding among children 0-35.9 months of age. \\
\hline 6. Minimum meal frequency: & 14. Bottle feeding: \\
\hline $\begin{array}{l}\text { Proportion of breastfed and non-breastfed children } 6-23.9 \text { months of age } \\
\text { who receive solid, semi-solid or soft foods (including milk feeds for non- } \\
\text { breastfed children) the minimum number of times or more. }\end{array}$ & Proportion of children 0-23.9 months of age who are fed with a bottle. \\
\hline 7. Minimum acceptable diet: & 15. Milk feeding frequency for non-breastfed children: \\
\hline $\begin{array}{l}\text { Proportion of children 6-23.9 months of age who receive a minimum } \\
\text { acceptable diet (apart from breast milk). }\end{array}$ & $\begin{array}{l}\text { Proportion of non-breastfed children } 6-23.9 \text { months of age who receive } \\
\text { at least two milk feedings (infant formula, cow's milk or other animal } \\
\text { milk). }\end{array}$ \\
\hline 8. Consumption of iron-rich or iron-fortified foods: & \\
\hline $\begin{array}{l}\text { Proportion of children 6-23.9 months of age who receive an iron-rich or } \\
\text { iron-fortified food that is specially designed for infants and young } \\
\text { children, or that is fortified in the home. }\end{array}$ & \\
\hline \multicolumn{2}{|l|}{ Note: } \\
\hline \multicolumn{2}{|l|}{ Indicators $2-8,10-12$ and $14-15$ are based on a 24 -hour recall period. } \\
\hline \multicolumn{2}{|c|}{ Indicators 1, 2, 7 and 8 are considered top priorities for reporting among the core indicators. } \\
\hline \multicolumn{2}{|c|}{$\begin{array}{l}\text { The seven food groups mentioned under indicator } 5 \text { are: grains, roots and tubers; legumes and nuts; dairy products (milk, yogurt, cheese); flesh foods (meat, fish } \\
\text { poultry and liver/organ meats); eggs; vitamin A rich fruits and vegetables; other fruits and vegetables. }\end{array}$} \\
\hline \multicolumn{2}{|c|}{$\begin{array}{l}\text { Minimum number of times mentioned under indicator } 6 \text { is defined as: two times for breastfed infants 6-8.9 months; three times for breastfed children } 9-23.9 \\
\text { months; four times for non-breastfed children 6-23.9 months. }\end{array}$} \\
\hline \multicolumn{2}{|c|}{$\begin{array}{l}\text { Indicator } 7 \text { is the sum of two fractions: (1) the proportion of breastfed children } 6-23.9 \text { months of age who had at least the minimum dietary diversity and the } \\
\text { minimum meal frequency during the previous day; plus (2) the proportion of non-breastfed children } 6-23.9 \text { months of age who received at least two milk } \\
\text { feedings and had at least the minimum dietary diversity and the minimum meal frequency during the previous day. }\end{array}$} \\
\hline Indicator 11 is the sum of exclusive breastfeeding under six months plus the prop & portion of children 6-23.9 months of age who received breast milk as well as \\
\hline
\end{tabular}

among the four top priority core indicators. In Pakistan, although breastfeeding is nearly universal, early initiation rates are not as high. In 1990-91, among the last born children, those for whom breastfeeding was initiated within the first hour and day of delivery stood at $8.5 \%$ (95\% CI: 7.6, 9.4) and 25.8\% (95\% CI: 24.5, 27.1) respectively [7]. The corresponding estimates in 2006-07 demonstrate marked improvement, with rates of $27.2 \%$ (95\% CI: 26.0, 28.3) and 65.5\% (95\% CI: 64.3, 66.8) respectively [3].

\section{Exclusive breastfeeding under six months}

The proportion of infants under six months who were being exclusively breastfed was $22.8 \%$ (95\% CI: 19.8 -
$25.7)$ in $1990-91$ [7], which had increased to $37.1 \%$ (95\% CI: 34.0, 40.2) by 2006-07 [3].

\section{Continued breastfeeding at one year}

The percentage of infants over 12 months and under 16 months who were continuing to breastfeed increased slightly from $78.2 \%(95 \%$ CI: $74.7,81.7)$ in 1990-91 [7] to $79 \%$ (95\% CI: $75.8,82.2)$ in 2006-07 [3]. The change, however, is not statistically significant.

\section{Introduction of solid, semi-solid or soft foods}

The proportion of infants aged 6 to 9 months who received solid/semi solid or soft food as a supplement was $32.1 \%$ (95\% CI: $27.5,36.7)$ [7] and 36.3\% (95\% CI: 
$32.4,40.2)$ [3] in 1990-91 and 2006-07 respectively, a statistically insignificant difference. (See Figure 1).

\section{Children ever breastfed}

Of all children born in the five years preceding the survey, the proportion who were ever breastfed was $93.5 \%$ (95\% CI: 92.9, 94.1) in 1990-91 [7], which was similar to the corresponding value in 2006-07, 94.3\% (95\% CI: $93.8,94.8)$ [3]. The percentage of women who breastfed their last child fell from $96 \%$ in 1998-99 [PIHS] to $92 \%$ in 2001-02 [PIHS 01-02]. According to the estimates of PSLM, the percentage was $96 \%$ in 2005-06, and remained stable till 2007-08. (See Table 3).

\section{Continued breastfeeding at two years}

Continued breastfeeding, in terms of the percentage of children 20-23 months of age breastfeeding, also did not change: $51.7 \%(95 \%$ CI: $45.9,57.4)$ in 1990-91 [7] and $54.9 \%$ (95\% CI: 49.9, 59.9) in 2006-07 [3].

\section{Age appropriate breastfeeding}

Age appropriate breastfeeding is defined as the sum of the proportion of infants less than 6 months who are exclusively breastfed, and those between 6-24 months who are receiving a complementary diet along with breast milk. The prevalence of age appropriate breastfeeding did not change in the approximately 15 -year period between the two DHS surveys: $48.2 \%$ (95\% CI: $46.2,50.1$ ) in $1990-91$ and $46.2 \%$ (95\% CI: 44.5, 47.9) in 2006-07.

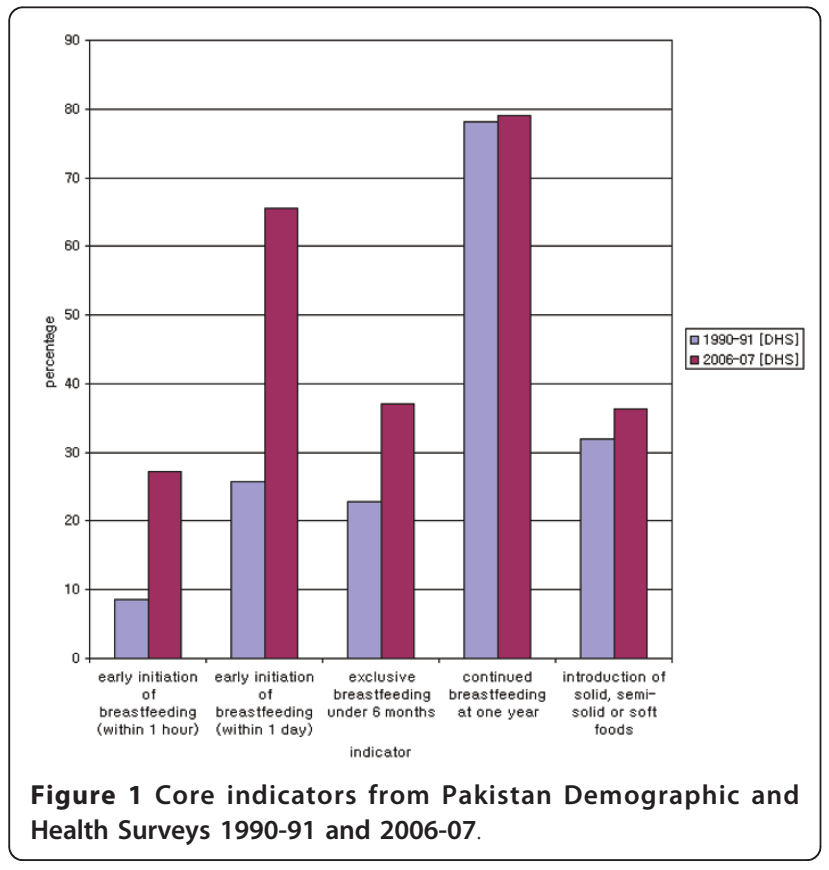

Table 3 Children ever breastfed

\begin{tabular}{lcc}
\hline Survey & Percentage & 95\% Confidence Interval \\
\hline DHS 1990-91 & 93.5 & $92.9,94.1$ \\
DHS 2006-07 & 94.3 & $93.8,94.8$ \\
PIHS 1998-99 & 96 & $\mathrm{~N} / \mathrm{A}^{*}$ \\
PIHS 2001-02 & 92 & $\mathrm{~N} / \mathrm{A}$ \\
PSLM 2005-06 & 96 & $\mathrm{~N} / \mathrm{A}$ \\
PSLM 2007-08 & 96 & $\mathrm{~N} / \mathrm{A}$ \\
\hline
\end{tabular}

N/A: Not available (unable to calculate because data are not available)

\section{Predominant breastfeeding under 6 months}

Predominant breastfeeding occurs when breast milk is the predominant source of nourishment for the infant, but the infant additionally receives water, water based drinks, and fruit juice [17]. The proportion of infants under 6 months of age who were predominantly breastfed in $2006-07$ was $18.8 \%$ (95\% CI: 16.3, 21.2) [3]. Sufficient data to calculate the corresponding value in the 1990-91 survey are not available. However, the proportion of infants under 6 months who received only plain water in addition to breast milk, which to some degree is an indicator of the predominant feeding status, was $11.0 \%(95 \%$ CI: 8.7, 13.2) in 1990-91 [7], which increased to $17.1 \%$ (95\% CI: $14.8,19.5)$ by $2006-07$ [3].

\section{Duration of breastfeeding}

The mean duration of any breastfeeding (of all the children born in the five years preceding the survey) decreased from 19.8 months in $1990-91$ to 18.3 in 200607 (of all the children born in the three years preceding the survey), while the duration of exclusive breastfeeding increased from 2.9 to 3.2 , and that of predominant/full breastfeeding from 4.9 to 5.6 months.

\section{Bottle feeding}

The use of pacifiers and bottles with nipples has been shown to interfere with successful breastfeeding [18], leading to reduced duration of breastfeeding, [19] and 'nipple confusion' in infants [20]. In third world countries such as Pakistan, bottle-feeding poses the additional risk of introducing pathogens into the infant, because of unhygienic practices during handling and preparation leading to increased susceptibility to diarrhea and infections [21,22]. The Baby Friendly Hospital Initiative of the World Health Organization specifically discourages giving artificial 'teats or pacifiers' to breastfeeding infants in its 'Ten steps to successful breastfeeding' [23]. The percentage of children under 24 months of age who were fed using a bottle with a nipple in 2006-07 was 34.1\% (95\% CI: 20.0, 23.5) [3]. Corresponding estimates are not given in the earlier survey. However, the prevalence of bottle feeding among breastfeeding children under 24 months, which may to 
some degree be an indicator of the prevalence of bottle feeding in all children (breastfeeding and not breastfeeding), was $21.8 \%$ (95\% CI: 32.5, 35.7). (See Figure 2).

\section{Milk feeding frequency for non-breastfed children}

The World Health Organization requires that nonbreastfeeding infants aged 6-24 months be given at least two milk feeds daily [24]. Milk feeding frequency however was not reported in any publication. But the percentage of non-breastfed children in the specified age group who were fed infant formula/other milk in the day or night preceding the interview was $91.9 \%$ in 2006 07 [3], while the data in the earlier DHS survey were insufficient to calculate this.

\section{Discussion}

The results presented here show trends in the core and optional indicators. While early initiation and exclusive breastfeeding have improved, continued breastfeeding at the first year, and the introduction of solid, semi-solid and soft foods have experienced no statistically significant change.

Data on five core indicators, namely: minimum acceptable diet, consumption of iron-rich or iron-fortified foods, minimum dietary diversity, and meal frequency, is lacking in the surveys studied, nor could it be retrieved from any other publication. The National Institute of Population Studies should consider including this information in future Demographic and Health Surveys so a more accurate analysis of the indicators of breastfeeding and complementary feeding can be made possible. The

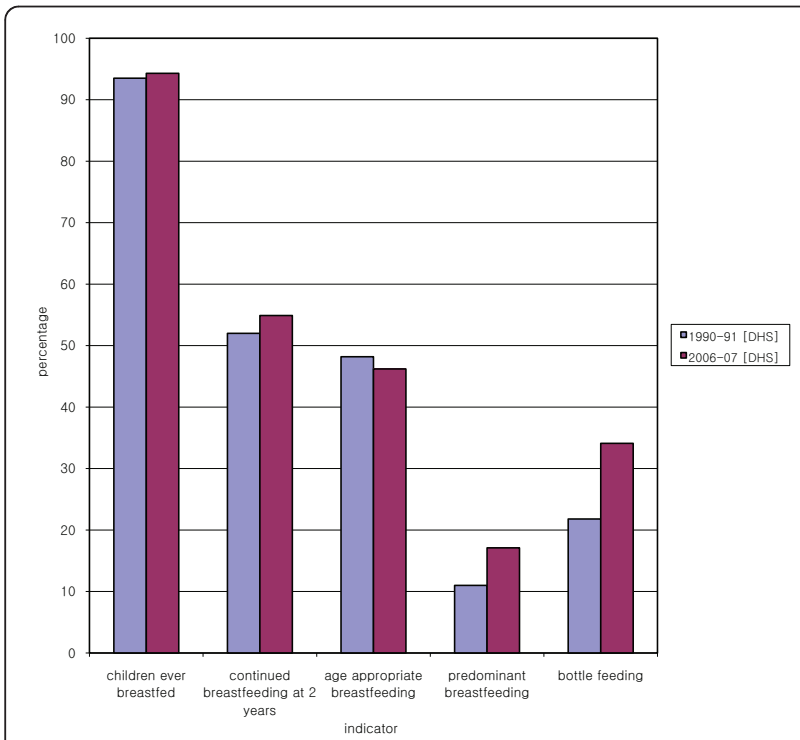

Figure 2 Optional indicators from Pakistan Demographic and Health Surveys 1990-91 and 2006-07.
Federal Bureau of Statistics may also like to consider this in its future relevant surveys.

The WHO optional indicators (continued breastfeeding at two years, age appropriate breastfeeding and the duration of breastfeeding) demonstrate decreased prevalence, while bottle feeding has increased. This suggests that these aspects of healthy breastfeeding require more concern. In order to achieve optimal results, it seems imperative for the MNCH program, WHO, UNICEF and other organizations working for the promotion of healthy breastfeeding practices to consider placing more emphasis on these aspects in their future workshops, training and other endeavors.

It is noteworthy that the confidence intervals for the indicators were calculated assuming a simple random mode of sampling. In DHS however, a multi-stage stratified sample was used, so the actual error margin is likely to be higher because of the principle of 'design effect' [3]. Hence, the apparent improvement in some indicators is likely to be even more modest.

The five indicators required in the WHO tool for the assessment of national practices policies and programs related to infant and young child feeding [4], displayed in Figure 3, show no improvement over time. Furthermore, the rating for bottle feeding has gone down from 'fair' to 'poor'. Also noteworthy is that three of the five indicators fall in the poor category, which suggests there is considerable scope for improving breastfeeding and complementary feeding practices. In one independent assessment of IYCF policies, practices and programs, Pakistan ranks $4^{\text {th }}$ among eight other countries in the region, including India, Afghanistan, Sri Lanka, Nepal, Bangladesh, Bhutan and Maldives, with a score of 75.5 out of 150 (Grade C), signifying low achievement [25].

In the backdrop of the economic crises that has loomed over the country, the recent devastating floods, and the ensuing striking rates of malnutrition, promotion of healthy breastfeeding practices has assumed an even more pivotal role. An enhanced cooperation among national and international NGOs and the government is crucial to addressing the issue. Interventions that are known to improve breastfeeding practices are not being effectively exploited; influencing public and private sector hospital policies, in particular, needs to be aggressively addressed. Furthermore, despite its import, research on the subject is lacking, and should be promoted to generate reliable data that can be used to guide the effective planning and development of interventions.

\section{Conclusions}

Data on breastfeeding indicators in Pakistan suggest an overall unsatisfactory status. Hence, there is much scope for improvement. Further programs should focus on 


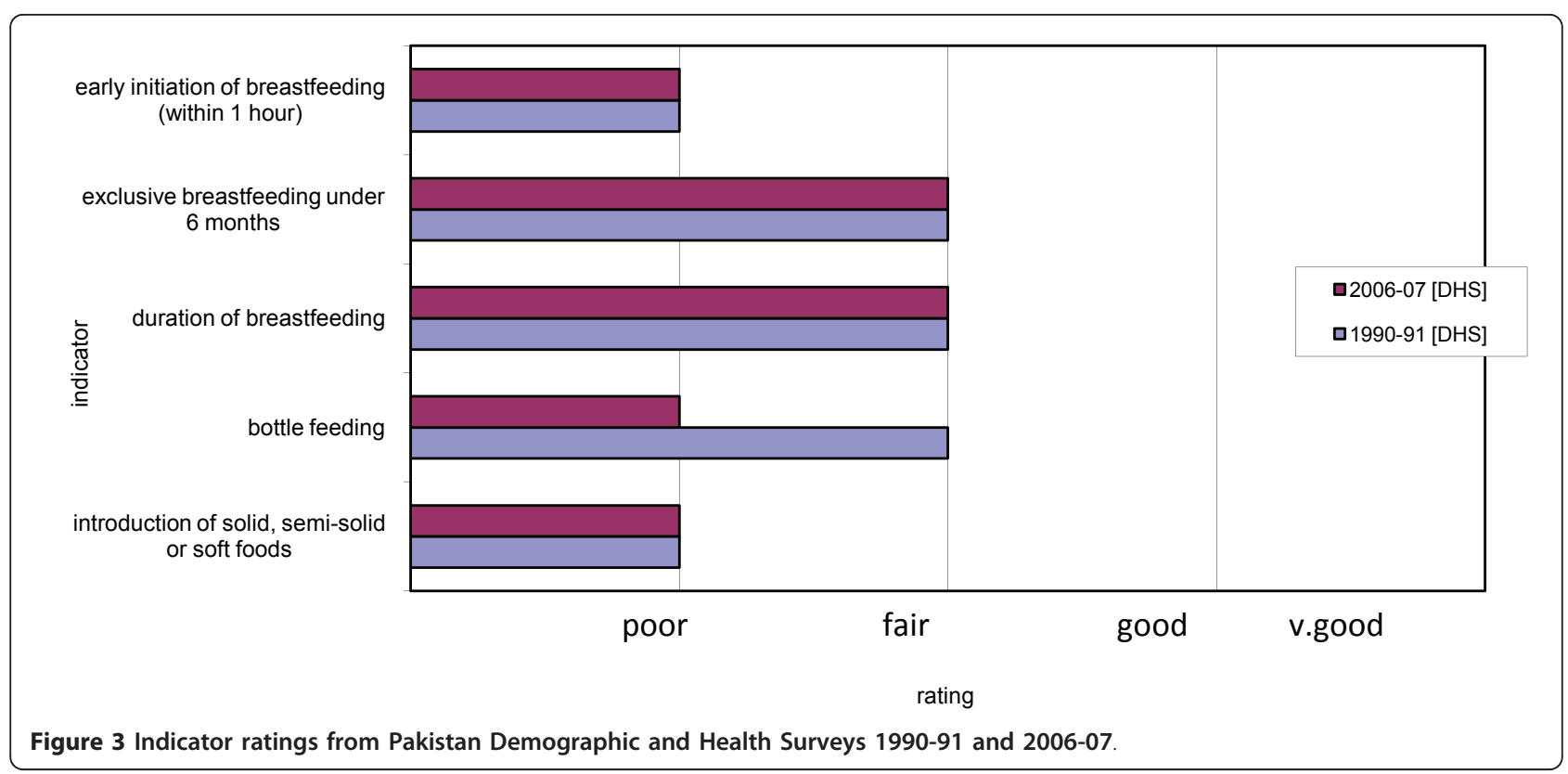

improving the following indicators that have shown no significant development: early initiation of breastfeeding, exclusive breastfeeding under six months, continued breastfeeding at two years, age appropriate feeding, and bottle feeding. Effective implementation of interventions that are known to improve breastfeeding practices is imperative, as is further research to yield data that can lead future endeavors.

\section{Additional material}

Additional file 1: Calculations. Calculations to estimate indicators of breastfeeding and complementary feeding practices.

\section{List of abbreviations}

PDHS: Pakistan Demographic and Health Survey; PIHS: Pakistan Integrated Household Survey (Federal Bureau of Statistics); PSLM: Pakistan Social and Living Standards Measurement Survey (Federal Bureau of Statistics)

\section{Acknowledgements}

I am grateful to Mr. Syed Arif Ali, Biostatistician, Research Department, Dow University of Health Sciences, Karachi, for assisting me with the statistical analysis of the data.

\section{Competing interests}

The author declares that they have no competing interests.

Received: 26 November 2010 Accepted: 21 October 2011 Published: 21 October 2011

\section{References}

1. World Health Organization: Infant and Young Child Feeding. Model Chapter for textbooks for medical students and allied health professionals. France: WHO; 2009

2. World Health Organization: Promoting proper feeding for infants and young children.[http://www.who.int/nutrition/topics/infantfeeding/en/ index.html].
3. National Institute of Population Studies (NIPS) [Pakistan], and Macro International Inc:: Pakistan Demographic and Health Survey 2006-07 Islamabad, Pakistan; 1992.

4. World Health Organization: Infant and Young Child Feeding: A Tool for Assessing National Practices, Policies and Programmes. Geneva; 2003.

5. Toma TS, Rea MF: Benefits of breastfeeding for maternal and child health: an essay on the scientific evidence. Cad Saude Publica 2008, 24(Suppl 2):S235-46.

6. National MNCH Program Maternal, Newborn and Child Health Program, Ministry of Health, Govt. of Pakistan: Emergency Obstetric Care:[http://www. mnch.gov.pk/eoc.php\#place"F"].

7. National Institute of Population Studies (NIPS) [Pakistan], and Macro International Inc.: Pakistan Demographic and Health Survey 1990-91 Islamabad, Pakistan; 1992.

8. A copy of Pakistan Integrated Household Survey - 1998-1999 could not be retrieved. The estimates quoted in the text are available in the following document:Federal Bureau of Statistics (PK). Pakistan Integrated Household Survey - 2001-02 Islamabad; 2002

9. Federal Bureau of Statistics (PK): Pakistan Integrated Household Survey - 2001 02 Islamabad; 2002.

10. Mahmud K, Ayazuddin, Awan R: Pakistan Social and Living Standard Measurement Survey - 2005-06 Islamabad; 2007.

11. Mahmud K, Ayazuddin, Awan R: Pakistan Social and Living Standard Measurement Survey - 2007-08 Islamabad; 2007.

12. EUPHIX: Set of infant and young child feeding indicators proposed by WHO.[http://www.euphix.org/object_document/05507n27421.html].

13. World Health Organization: Indicators for assessing infant and young child feeding practices (Part I). France; 2008.

14. World Health Organization: Indicators for assessing infant and young child feeding practices (Part III). France; 2008.

15. Baker EJ, Sanei LC, Franklin N: Early initiation of and exclusive breastfeeding in large-scale community-based programmes in Bolivia and Madagascar. J Health Popul Nutr 2006, 24(4):530-9.

16. Renfrew MJ, Lang S, Woolridge MW: Early versus delayed initiation of breastfeeding. Cochrane Database Syst Rev 2000, 2: CD000043.

17. EUPHIX: Definitions of breastfeeding recommended by WHO.[http://www. euphix.org/object_document/o5506n27421.html].

18. Righard L: Early enhancement of successful breast-feeding. World Health Forum 1996, 17(1):92-7.

19. Righard L: Are breastfeeding problems related to correct breastfeeding technique and the use of pacifiers and bottles? Birth 1998, 25(1):40-4

20. Neifert M, Lawrence $R$, Seacat J: Nipple confusion: toward a formal definition. J Pediatr 1995, 126(6):S125-9. 
21. D'souza RM, Bryant JH: Determinants of childhood mortality in slums of Karachi, Pakistan. J Health Popul Dev Ctries 1999, 2(1):33-44.

22. Redmond EC, Griffith CJ, Riley S: Contamination of bottles used for feeding reconstituted powdered infant formula and implications for public health. Perspect Public Health 2009, 129(2):85-94

23. World Health Organization: Evidence for the Ten Steps to Successful Breastfeeding. Geneva; 1998

24. World Health Organization: Indicators for assessing infant and young child feeding practices (Part II). France; 2008.

25. Gupta A, Arora V, Bhatt B: The State of the World's Breastfeeding; Pakistan Report Card 2006. Delhi (India); 2006.

doi:10.1186/1746-4358-6-15

Cite this article as: Hanif: Trends in breastfeeding and complementary

feeding practices in Pakistan, 1990-2007. International Breastfeeding Journal 2011 6:15.

\section{Submit your next manuscript to BioMed Central} and take full advantage of:

- Convenient online submission

- Thorough peer review

- No space constraints or color figure charges

- Immediate publication on acceptance

- Inclusion in PubMed, CAS, Scopus and Google Scholar

- Research which is freely available for redistribution

Submit your manuscript at www.biomedcentral.com/submit 